\title{
Heat Transfer Analysis of an Integrated Double Skin Façade and Phase Change Material Blind System
}

\section{Yilin LI ${ }^{\mathrm{a}, \mathrm{b}, *}$, Jo DARKWA ${ }^{\mathrm{b}}$, Georgios KOKOGIANNAKIS ${ }^{\mathrm{c}}$}

a, Research Centre of Green Building and New Energy, Tongji University, 1239\# Siping Road, Shanghai, P.R.China

b, Faculty of Engineering, University of Nottingham, University Park, Nottingham, NG7 2RD, UK c, School of Mechanical, Materials and Mechatronic Engineering, Sustainable Building Research Centre, University of Wollongong, Innovation Campus, Fairy Meadow, NSW 2519, Australia

${ }^{*}$ Corresponding author: Yilin LI

Email: yilin.li@tongji.edu.cn

\begin{abstract}
In this study, the heat transfer in an integrated double skin facade (DSF) and phase change material (PCM) blind system has been theoretically analysed. Both heat transfer and airflow models with CFD methods have been developed for the integrated DSF and PCM blind system. Data from an existing typical DSF building have been obtained in order to define input parameters for the simulation exercise and validate the numerical models. The temperature and velocity fields in DSF with the PCM blind system has been predicted under overheating scenario using the ANSYS Workbench FLUENT software and been compared with case of conventional aluminium blind system. This study has shown that the integrated PCM blind system was able to reduce the average air temperature and outlet temperature of the DSF while improving the convective heat transfer between the cavity air and the blades. Compared with the aluminium blind, the PCM blind can absorb large amount of excessive heat in the cavity. Overall the integrated PCM blind system has the potential to be used as an effective thermal management device for minimising the overheating effect in DSFs.
\end{abstract}

Keywords: Double Skin Facade; PCM; heat transfer analysis; CFD 


\begin{tabular}{|c|c|}
\hline \multicolumn{2}{|c|}{ Nomenclature } \\
\hline$A$ & area $\left(\mathrm{m}^{2}\right)$ \\
\hline$C_{p}$ & specific heat $(\mathrm{kJ} / \mathrm{kg} \cdot \mathrm{K})$ \\
\hline$Q$ & heat $(\mathrm{W})$ \\
\hline E & total energy \\
\hline$H$ & enthalpy $(\mathrm{kJ} / \mathrm{kg})$ \\
\hline$\Delta H$ & latent heat $(\mathrm{kJ} / \mathrm{kg})$ \\
\hline$T$ & temperature $(\mathrm{K})$ \\
\hline$\Delta T$ & temperature difference \\
\hline$T_{0}$ & $\begin{array}{l}\text { operating temperature/surface temperature } \\
\text { of objective }\end{array}$ \\
\hline$T_{s}, T_{\infty}$ & $\begin{array}{l}\text { temperature on surface/of fluid far from } \\
\text { surface }\end{array}$ \\
\hline$S_{\varphi}$ & user-defined source term \\
\hline$\Gamma_{\phi}$ & the diffusion coefficient \\
\hline$\varphi$ & $\begin{array}{l}\text { a common variable that refers to the } \\
\text { continuity equation, temperature, and } \\
\text { velocity }\end{array}$ \\
\hline$\vec{U}$ & velocity vector \\
\hline$G_{\text {sol }}$ & Solar irradiance \\
\hline $\overrightarrow{J_{j}}$ & diffusion flux of species $j$ \\
\hline$h$ & $\begin{array}{l}\text { convective heat transfer coefficient } \\
\left(\mathrm{W} / \mathrm{m}^{2} \mathrm{~K}\right) / \mathrm{sensible} \text { enthalpy }(\mathrm{kJ} / \mathrm{kg})\end{array}$ \\
\hline$k, k_{e f f}$ & $\begin{array}{l}\text { thermal conductivity/effective conductivity } \\
(\mathrm{W} / \mathrm{mK})\end{array}$ \\
\hline$t$ & time (s) \\
\hline$\rho, \rho_{0}$ & density/reference density \\
\hline$v$ & kinematic viscosity \\
\hline$\mu$ & molecular viscosity \\
\hline$\mu_{t}$ & turbulent viscosity \\
\hline$s$ & path length \\
\hline$\alpha$ & $\begin{array}{l}\text { absorption coefficient/expansion } \\
\text { coefficient of air }\end{array}$ \\
\hline$\beta$ & $\begin{array}{l}\text { thermal expansion coefficient/liquid } \\
\text { fraction }\end{array}$ \\
\hline$\tau$ & transmittance of the DSF outer glass skin \\
\hline$\varepsilon$ & emissivity \\
\hline$\sigma^{\prime}$ & $\begin{array}{l}\text { Stefan-Boltzmann constant/solid } \\
\text { angle/turbulent Prandtl number }\end{array}$ \\
\hline$\delta$ & characteristic length of geometry \\
\hline Subsc & ipts \\
\hline net & net heat gain of DSF \\
\hline sol & total solar radiation on the DSF \\
\hline refl & reflected solar radiation \\
\hline ref & reference value \\
\hline
\end{tabular}

\begin{tabular}{|ll|}
\hline$a b s$ & absorbed solar radiation \\
tra & transmitted solar radiation \\
1 & external glass skin of the DSF \\
conv & internal glass skin of the DSF \\
$r a d$ & radiative heat transfer \\
$a$ & cavity air \\
$b$ & blind \\
$k$ & turbulence kinetic energy \\
$i$ & indoor \\
$o$ & outdoor \\
$p$ & PCM layer of the blind \\
$s$ & substrate of the blind \\
$\varepsilon$ & dissipation rate \\
$x, r, z$ & axial/radial/swirl coordinate \\
\hline
\end{tabular}




\section{Introduction}

The building sector is responsible for approximately $40 \%$ of the world's total annual energy consumption [1]. This situation has therefore raised the need for applying various sustainable design concepts for reducing energy consumption in buildings [2]. As a form of envelope in modern buildings, double skin façade (DSF) has already become a common architectural design feature around the world with great potential in energy saving [3]. DSFs are types of building envelopes consisting of external and internal skins with intermediate space between them. The DSFs have advantages such as providing natural ventilation, natural daylight, and acoustic barrier to buildings [4]. Kim et al. [5] also proved that DSFs can be used to reduce energy consumptions in buildings during both heating and cooling seasons while maintaining indoor comfort levels. However, studies conducted by Tascon [6] revealed that DSFs tend to experience overheating problems during warm seasons.

To this end various methods have been studied as possible solutions for minimising the overheating problems. For instance Jager et al. [7] indicated that the overheating problem can be avoided by ensuring a minimum distance between the internal and external panes of a DSF due to greater stack effect and adequate air flow in wider cavities. Wigginton et al. [8] stated the sizes of ventilation openings are crucial parameters influencing the cavity temperature since they determine the efficiency of air exchange between DSF and external environment. Fallahi et al. [9] demonstrated that utilisation of concrete slats as thermal mass in mechanically ventilated DSF can help to decrease the risk of overheating. Recent studies have further reported that the effectiveness of concrete can be enhanced by incorporating phase change materials (PCMs) [10]. Gracia et al. $[11,12]$ integrated a PCM system into the air channel of a ventilated facade and observed reduction of overheating effect during the PCM solidification and melting periods. Even though the above highlighted studies have provided possible solutions to the overheating effect in DSFs, it is clear that there are still some technical and scientific barriers that need to be overcome. 
The focus of this paper is on the development of a physical-mathematical model of an integrated DSF and PCM

blind system by using CFD methods. The numerical results are validated by comparing with experimental measurements. The heat transfer behaviour of the integrated system under overheating scenario is then evaluated and compared with conventional aluminium system.

\section{Background}

Double skin facades have been widely applied in different climatic area around world [13, 14]. This study mainly investigates the hot summer and cold winter regions where DSFs are favourable applications in winter and mid-season [15], but face a major challenge of overheating in summer which tend to result in unpleasant indoor environment and increase the cooling loads in buildings [16, 17]. Previous researchers have raised the overheating problems associated with DSFs and come up with several solutions to dispel the problems. Tascon [5] raised that the main causes of overheating in DSF which included ineffective removal of heat stored within the DSF system, inappropriate location and size of shading devices, and inadequate operations of the DSF for specific thermal environmental conditions. Jager et al. [6] and Wigginton et al. [7] reported physical considerations at design stage of DSFs such as ensuring a minimum distance between the outer and inner skins and adjusting the sizes of openings for better ventilation in the cavity. Other flexible methods such as utilisation of shading devices (venetian blind as the commonest one [15]), integration of thermal mass (Fallahi et al. [8]), application of energy storage materials such as phase change materials (De Gracia et al. [10]), and thermal control strategies (Haase et al. [18, 19]) have also been investigated to assess their effectiveness in removing excess heat gains in DSFs.

Even though the above methods may be adopted in DSF systems as solutions to overheating effect, there are some barriers to be overcome and improvements to be made. For instance, extensive research have been conducted on venetian blinds and prove that factors such as blind position [20-22], slat tilt angle [10, 22], and colour and size of the blind [21] can influence the DSF performance. The main problem of the existing venetian 
blind systems for DSFs is the high surface temperature caused by solar absorption on the blinds [23]. The consequences are that the blinds may act as solar heaters which radiate heat and contribute to overheating in adjacent space. Fallahi et al. [8] investigated different integrations of concrete materials and DSFs and revealed limitations of the thermal mass system included comparably low energy storage capacity of the concrete and sacrifice of natural illumination through the DSF.

Phase change material (PCM), as a thermal energy storage medium, can increase the thermal capacity of the building components and thus contribute to reducing heating and cooling loads in buildings [24]. Since PCMs have high energy storage capacity over a narrow temperature, large amount of heat can be stored during the melting processes. De Gracia et al. $[10,11]$ adopted PCM in DSF system and found it can prevent the overheating effect between the PCM solidification and melting periods. However, it is necessary to optimise the PCM-DSF system for achieving certain level of natural illumination and flexible operation under various weather conditions. By incorporating proper PCMs into the blind system, it is possible to embody the advantages and overcome the operational limitations of the currently existing thermal management strategies and systems the limitations of conventional venetian blind and thermal mass system can be eliminated. Weinlaeder et al. [25] monitored an integrated PCM solar blind system in a building and achieved some level of temperature reduction in comparison with a conventional blind. However, the systems which consisted of macroencapsulated salt hydrate panels suffered from low energy storage efficiency and solidification issues. To the author's knowledge, there is still lack of numerical and experimental information on the effectiveness and performance of PCM blind systems in DSFs.

Taken the above points, the present study proposed an integrated microencapsulated composite laminated PCM blind system, and investigates its thermal improvements towards minimising the overheating effect and thus enhance the thermal performance of DSFs. After the development of physical and mathematical models, a case study is conducted with a DSF test facility under summer condition for the purpose of model validation. 


\section{Model Descriptions}

Fig. 1a shows a physical model of an integrated naturally ventilated DSF system containing a number of blades in the air cavity and Fig. $1 \mathrm{~b}$ presents the geometric dimensions of the modelled integrated system. By integrating PCM blind in the DSF system, it is intended to absorb any excess solar heat through the external glass skin which may be trapped in the DSF cavity, thus in this way prevents additional heat gain into the adjacent indoor area in warm seasons.

Previous investigations carried out by Darkwa et al. $[26,27]$ have shown that laminated composite PCM with narrow phase-change zone was much more thermally effective than randomly mixed PCMs. For this reason a multilayer blind structure consisting of laminated composite PCM blades is proposed as presented in Fig. 1c. Each blade has a multilayer structure consisting of a laminated PCM layer and a substrate. The blind system was assumed to be located in the mid-section of the DSF with the slats tilted at an angle of $30^{\circ}$. When the temperature in the cavity increases above the melting temperature of the PCM, the PCM layer can absorb the solar heat trapped in the DSF cavity. The stored heat is then expected to be discharged and removed by means of natural or mechanical ventilation when the temperature in the cavity drops below the solidification temperature of the PCM. For the purpose of comparison, DSF containing conventional aluminium blind was also studied as shown in Fig. 1c. The physical properties of the integrated systems with PCM and aluminium blinds are presented in Tab. 1. For the benefit of simulation exercise, data for commercially available PCM product PX35 of RUBITHERM company [28] were adopted. The technical data of PX35 is shown in Tab. 1, while the DSC experimental test curve of PX35 is demonstrated in Fig. 2.

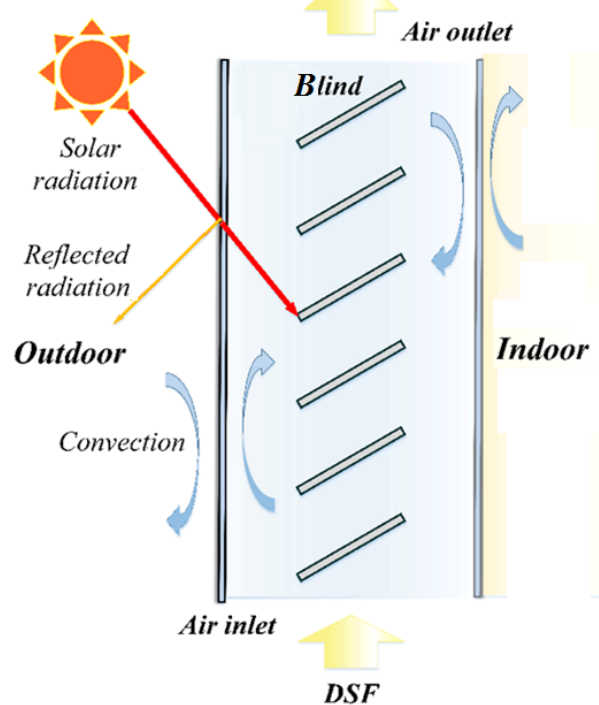

(a)

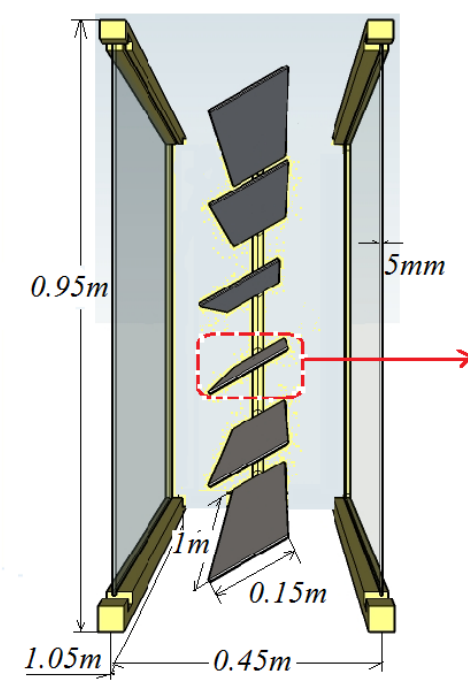

(b)

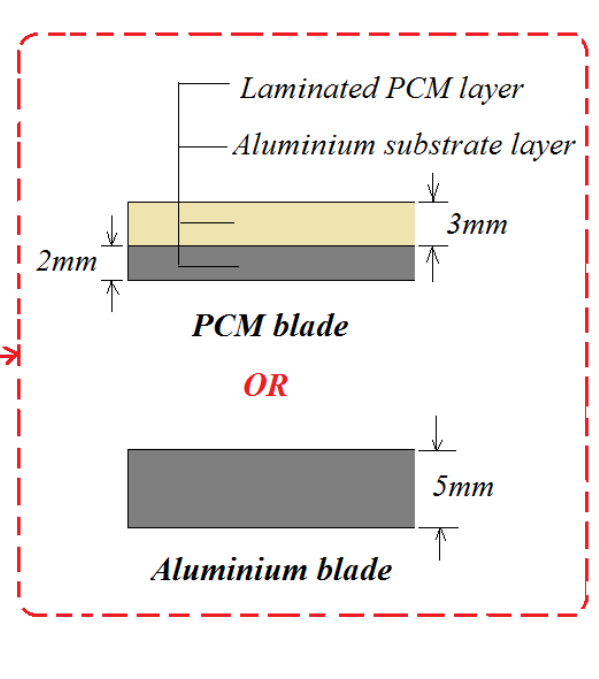

(c) 
Figure 1: Integrated DSF and blind system

(a) Schematic diagram (b) Dimensions of the modelled system (c) Details of the PCM/aluminium blade

Table 1: Physical properties of the integrated systems

\begin{tabular}{|c|c|c|c|c|c|c|c|c|c|c|}
\hline \multirow[t]{2}{*}{ Material } & \multirow{2}{*}{$\begin{array}{l}\text { Density } \\
\left(\mathrm{kg} / \mathrm{m}^{3}\right)\end{array}$} & \multirow{2}{*}{$\begin{array}{l}\text { Specific } \\
\text { heat } \\
(\mathrm{J} / \mathrm{kg} \cdot \mathrm{K})\end{array}$} & \multirow{2}{*}{$\begin{array}{l}\text { Heat } \\
\text { storage } \\
\text { capacity } \\
(\mathrm{KJ} / \mathrm{kg})\end{array}$} & \multirow{2}{*}{$\begin{array}{l}\text { Melting } \\
\text { temperature } \\
\left({ }^{\circ} \mathrm{C}\right)\end{array}$} & \multirow{2}{*}{$\begin{array}{l}\text { Thermal } \\
\text { conductivity } \\
(\mathrm{W} / \mathrm{m} \cdot \mathrm{K})\end{array}$} & \multirow[t]{2}{*}{$\begin{array}{l}\text { Reflec } \\
\text { tivity }\end{array}$} & \multicolumn{2}{|l|}{ Emissivity } & \multicolumn{2}{|c|}{$\begin{array}{l}\text { Refractive Absorptivity } \\
\text { index }\end{array}$} \\
\hline & & & & & & & External & Internal & & \\
\hline Glass & 2500 & 966 & - & - & 1.1 & - & 0.84 & 0.84 & 1.5 & 0.15 \\
\hline $\begin{array}{l}P C M \\
(P X 35)\end{array}$ & 650 & $\begin{array}{l}\text { See } \\
\text { Fig. } 2\end{array}$ & $\begin{array}{l}\text { See } \\
\text { Fig.2 }\end{array}$ & $29-36$ & 0.1 & 0.52 & 0.9 & 0.9 & - & 0.8 \\
\hline Aluminium & 2719 & 871 & - & - & 202.4 & 0.67 & 0.7 & 0.7 & 1.44 & 0.18 \\
\hline
\end{tabular}

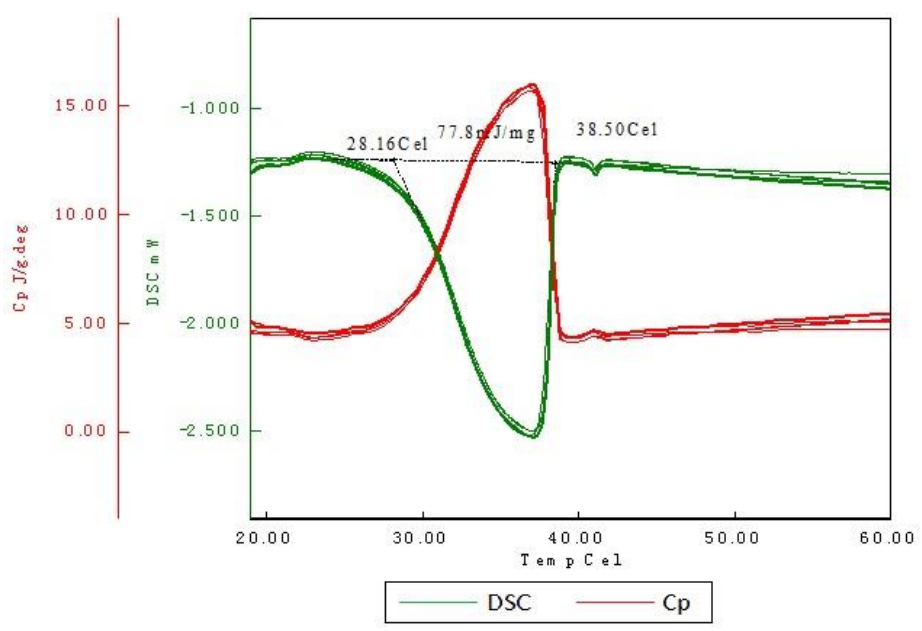

Figure 2: DSC curves for PX35 sample

\section{Modelling and Simulation}

Previous studies by Park et al. [29] and Yuan et al. [30] have shown that analytical lumped models can be used for understanding and analysing heat transfer processes in DSF systems. Other approaches such as airflow network model [31], control volume approach [32], and zonal approach [33] have been used to investigate more detailed airflow and heat transfer behaviours in DSF systems. However Computational Fluid Dynamics (CFD) method has proved to be the most accurate approach [15] and for that reason it was used for evaluating the heat and air flow distribution profiles in the DSF.

\subsection{Heat Transfer Model}


As shown in Fig. 3, there are multiple heat transfer pathways involving convection, conduction and radiation which exist in the DSF and PCM integrated system based on the following assumptions:

- Both convective and radiative heat transfer exist on the surface of the PCM blind.

- Only one-dimensional conduction is considered within each PCM blade and convective heat transfer is negligible.

- The PCM is homogeneous and isotropic with constant thermophysical properties except its enthalpy.

- The thermophysical properties of the aluminium substrate are constant.

- The tilt angle of the blind corresponds with the local latitude. There is no transmitted solar radiation on the internal glass skin of the DSF due to the length of the blade and the tilt angle of the blind.

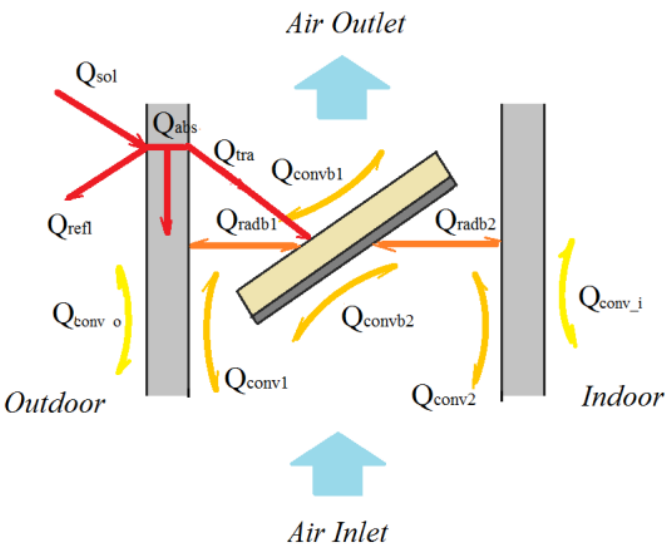

(a) Schematic of the integrated DSF system

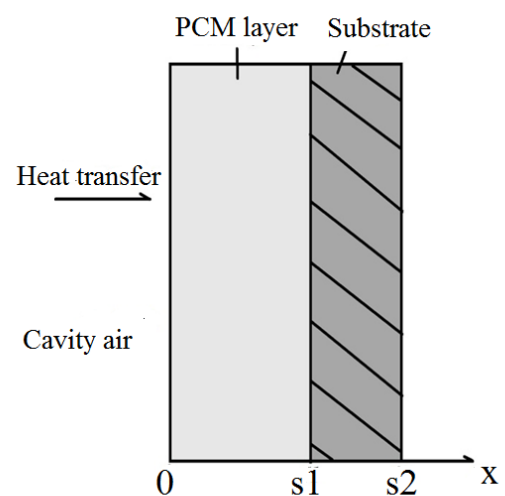

(b) Sectional view of a PCM blade

Figure 3: Heat transfer paths in the integrated system

As Fig. 3(a) shows, the net solar heat gain $\left(\mathrm{Q}_{\mathrm{net}}\right)$ into the DSF system can be expressed as:

$$
Q_{\text {net }}=Q_{\text {sol }}-Q_{\text {refl }}-Q_{\text {conv_o }}-Q_{\text {conv_ } i}
$$

Where

$$
\begin{aligned}
& Q_{s o l}=Q_{a b s}+Q_{t r a}+Q_{\text {refl }} \\
& Q_{a b s}=\alpha \times A_{1} \times G_{s o l} \\
& Q_{t r a}=\tau \times A_{1} \times G_{s o l}
\end{aligned}
$$

\section{Therefore}




$$
Q_{\text {net }}=Q_{a b s}+Q_{t r a}-Q_{c o n V_{-} o}-Q_{c o n V_{-} i}
$$

The total heat transfers to the PCM blade $\left(Q_{b}\right)$ can be expressed as:

$$
Q_{b}=Q_{\text {tra }}+Q_{\text {rad_b1 }}+Q_{\text {conv_b } b 1}
$$

As shown in Fig. 3(b), only one-dimensional conduction is considered within the PCM layer and therefore it can also be expressed as:

$$
Q_{b}=\left.k_{p} \frac{d T_{p}}{d x}\right|_{x=0}
$$

The energy equation of the PCM layer can be written as:

$$
\frac{\partial}{\partial t}\left(\rho_{p} H\right)=k_{p} \frac{\partial^{2} T_{p}}{\partial x^{2}}
$$

Where $\mathrm{h}$ is the sensible heat, $\Delta \mathrm{H}$ is the latent heat:

$$
\begin{aligned}
& H=h+\Delta H \\
& h=h_{\text {ref }}+\int_{T_{r e f}}^{T} c_{P p} d T
\end{aligned}
$$

The heat conducted from the PCM layer to the substrate on the interface s1 can be expressed as:

$$
\left.k_{p} \frac{d T_{p}}{d x}\right|_{x=s 1}=\left.k_{s} \frac{d T_{s}}{d x}\right|_{x=s 1}
$$

The energy equation within the substrate can be calculated as:

$$
\rho_{s} c_{P s} \frac{\partial T_{s}}{\partial t}=k_{s} \frac{\partial^{2} T_{s}}{\partial x^{2}}
$$

The heat transferred to interface s2 of the substrate $\left(Q_{s}\right)$ can be expressed as follows:

$$
\begin{aligned}
& Q_{s}=\left.k_{s} \frac{d T_{s}}{d x}\right|_{x=s 2} \\
& Q_{s}=Q_{\text {rad_b2 }}+Q_{\text {conv_b2 }}
\end{aligned}
$$

The total heat transfer from the cavity air $\left(Q_{a}\right)$ can therefore be calculated as:

$$
Q_{a}=C_{P a} m_{a} \Delta T_{a}
$$


$Q_{a}=Q_{c o n v_{-} 1}+Q_{c o n v_{-} 2}+Q_{c o n v_{-} b 1}+Q_{c o n v_{-} b 2}$

\subsection{Airflow Model}

In order to simplify modelling of the airflow in the DSF, the following assumptions were made:

- The airflow is treated as 2-dimensional incompressible flow with constant air density.

- There are turbulences in the cavity due to the presence of PCM blades.

The general governing equations for the fluid domain are developed by using Navier-Stokes equations while the buoyancy effect of air is simulated with Boussinesq approximation [34]:

$$
\begin{aligned}
& \frac{\partial(\rho \phi)}{\partial t}+\nabla(\rho \vec{U} \phi)=\nabla\left(\Gamma_{\phi} g r a \phi\right)+S_{\phi} \\
& \rho=\rho_{0}(1-\alpha \Delta T)
\end{aligned}
$$

The fluid regime in natural convection is governed by the dimensionless numbers Grashof number (Gr) and Rayleigh number (Ra). The Grashof number provides the main criterion in determining whether the fluid flow is laminar or turbulent while Rayleigh number is often used to measure the strength of the buoyancy-induced flow. These important dimensional numbers can be expressed as follows:

$$
G r=\frac{g \Delta \rho V}{\rho v^{2}}=\frac{g \beta \Delta T V}{v^{2}}=\frac{g \beta\left(T_{s}-T_{\infty}\right) \delta^{3}}{v^{2}}
$$

Where

$$
\begin{aligned}
& \beta=-\frac{1}{\rho}\left(\frac{\partial \rho}{\partial T}\right)_{P} \\
& R a=G r \operatorname{Pr}=\frac{g \beta \Delta T L^{3} \rho}{\mu \alpha}=\frac{g \beta\left(T_{s}-T_{\infty}\right) \delta^{3}}{v^{2}} \operatorname{Pr}
\end{aligned}
$$

Where

$$
\begin{aligned}
& \operatorname{Pr}=\frac{v}{\alpha}=\frac{\mu C_{p}}{k} \\
& \alpha=\frac{k}{\rho c_{P}}
\end{aligned}
$$


Pr is Prandtl number which describes the relative thickness of the velocity and the thermal boundary layers. It can be used to investigate the relationships between the surface velocity and the surface temperature in determining the convective heat transfer coefficient. As previous research has summarised, the higher the velocity on the plate surface, the greater the convective heat transfer coefficient [35].

\subsection{Simulation process}

CFD simulation software ANSYS FLUENT 14.0 was used for simulating the airflow and temperature distributions in the integrated DSF system. ANSYS FLUENT provides several turbulence and radiation models for solving problems involving turbulent flows and radiation. RNG $k-\varepsilon$ model was selected as the turbulence model since it is applicable for a wider class of flows than the standard $k$ - $\varepsilon$ model $[34,36]$. The discrete ordinates (DO) model was applied as the radiation model due to its ability in solving most radiation problems. For the purpose of comparison, two cases of integrated systems were simulated: Case 1 (DSF containing PCM blind) and Case 2 (DSF containing conventional aluminium blind) with both under overheating conditions.

\subsubsection{Meshing}

The mesh of the computational domain and mesh features are demonstrate in Fig. 4 and Tab. 2. Particular attention was paid on the mesh density and quality in order to achieve accurate results. Both quadrate and triangle cells were generated for the geometric model. The mesh was refined near the solid surfaces (wall boundaries and blind) with dense cell distribution in DSF cavity, and then gradually increased toward the air cavity in order to account for the boundary layer effect. The mesh independence were tested through a series of mesh refinements, and further refinement gave little difference on the main thermodynamic parameters.

The average of the Element Quality (ranges from 0 to 1 , where values close to 1 correspond to good quality) was obtained as 0.9587 and the minimum was 0.5642 ; the average Skewness (ranges from 0 to 1 , where values close to 0 correspond to good quality) was 0.05498 and the maximum was 0.7072 ; the average Orthogonal 
Quality (ranges from 0 to 1 , where values close to 1 correspond to good quality) was 0.9667 whereas the minimum was equal to 0.59 . This indicate that the mesh quality is acceptable for the simulation since most of the Element Quality, Skewness, and Orthogonal values for the meshes are close to the good quality values [34].

Table 2: $\quad$ Mesh features

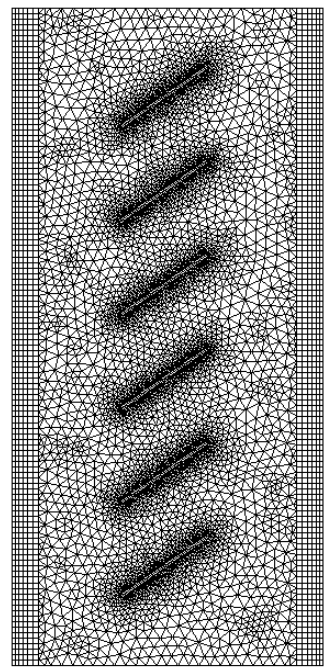

Mesh Number

Nodes 16216

Elements $\quad 12624$

Element Quality

Min $\quad 0.5642$

Max 0.9999

Average $\quad 0.9587$

Skewness

Min $\quad 1.3057 \mathrm{e}-10$

Max $\quad 0.7072$

Average $\quad 5.4983 \mathrm{e}-2$

Orthogonal Quality

Min $\quad 0.5900$

Max $\quad 1.0000$

Average $\quad 0.9667$

Figure 4: Mesh of the computational domain

\subsubsection{Boundary conditions and solver set-up}

The boundary conditions are set up as: velocity inlet for DSF inlet at the bottom, pressure outlet for DSF outlet at the top, and walls with no slip boundary conditions for the DSF glass skins and blind surface. For the solver solutions, SIMPLE scheme was selected as the pressure-velocity coupling method while second order approximations were used as differential equations solutions. The time step for the simulation was 10 s for 8640 steps covering a working cycle of the PCM blind system.

The ambient environmental data for the hottest month (July) of the year 2014 were obtained from an existing demonstration DSF building - the Centre for Sustainable Energy Technologies (CSET) building (Fig. 5) located in the University of Nottingham Ningbo China. As shown in Fig. 6, time-dependent ambient temperature and global solar radiation for the measured date was fitted into polynomial functions and 
introduced as a dynamic boundary condition to the CFD solver via user defined functions in FLUENT. DSF data and additional air properties were also adopted from recent studies on the same building by Darkwa et. al $[37,38]$ as summarised in Tab. 3.

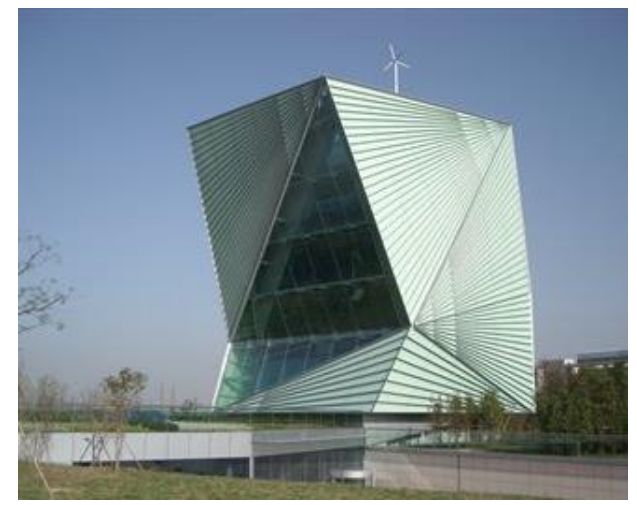

Figure 5: The CSET building

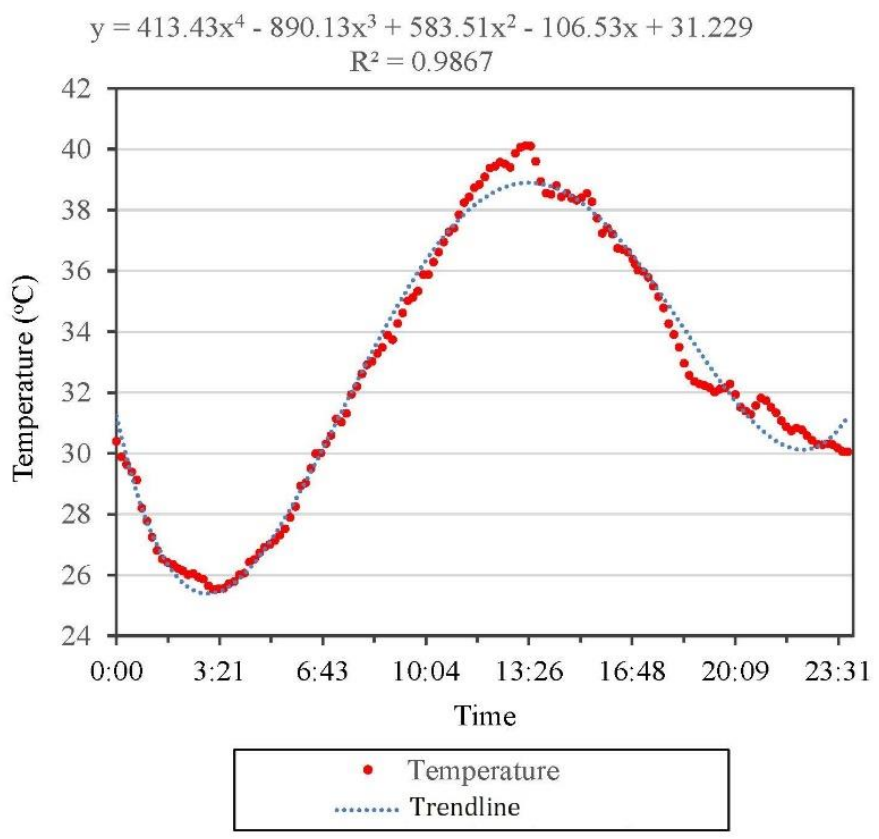

(a) Ambient temperature 


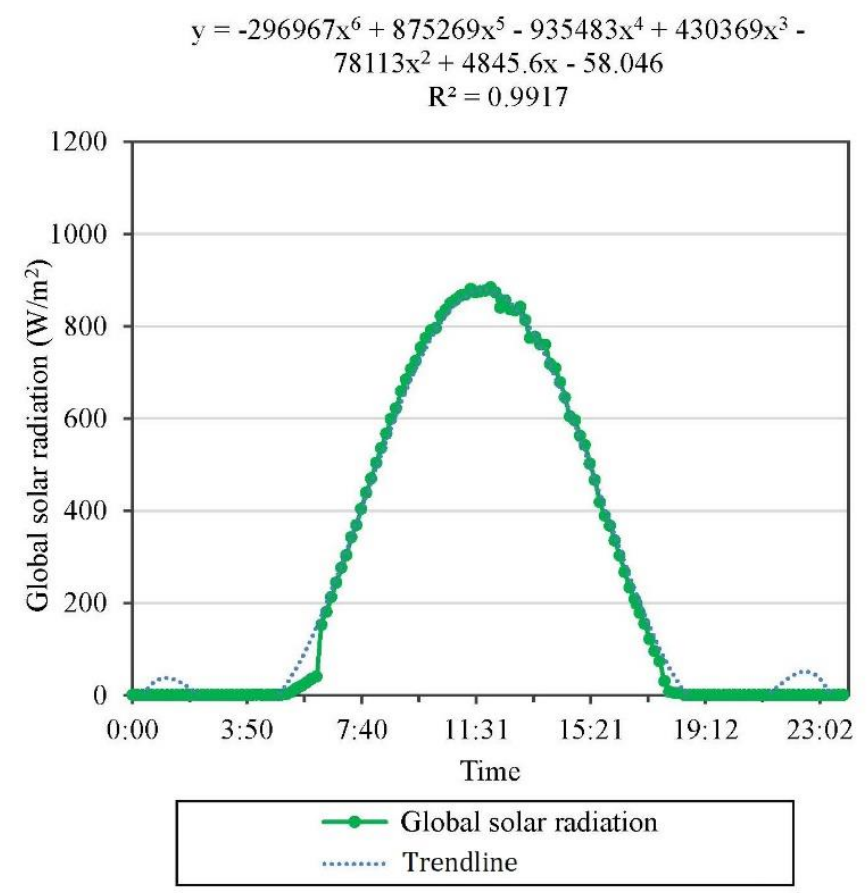

(b) Global solar radiation

Figure 6: Ambient environmental data

Table 3: DSF data and air properties

\begin{tabular}{lll}
\hline Item & Value & Unit \\
\hline$D S F$ & & \\
External skin temperature & 38.11 & ${ }^{\circ} \mathrm{C}$ \\
Internal skin temperature & 35.98 & ${ }^{\circ} \mathrm{C}$ \\
Cavity air temperature & 36.36 & ${ }^{\circ} \mathrm{C}$ \\
Inlet air velocity & 0.45 & $\mathrm{~m} / \mathrm{s}$ \\
\hline $\begin{array}{l}\text { Air properties } \\
\text { Thermal conductivity }\end{array}$ & 0.02 & $\mathrm{~W} / \mathrm{m} \cdot \mathrm{K}$ \\
Kinematic viscosity $(v)$ & 15.11 & $\mathrm{~mm} / \mathrm{s}$ \\
Density $(\rho)$ & 1.2 & $\mathrm{~kg} / \mathrm{m}^{3}$ \\
Thermal diffusivity $(\alpha)$ & 22.5 & $\mathrm{~mm} / \mathrm{s}$ \\
Specific heat $\left(c_{\mathrm{p}}\right)$ & 1 & $\mathrm{~kJ} / \mathrm{kg} \cdot \mathrm{K}$ \\
Prandtl number $\left(\operatorname{Pr}_{\mathrm{t}}\right)$ & 0.71 & \\
\hline
\end{tabular}

\subsection{Numerical Model Validation}

In order to validate the numerical models, a scale model test facility was installed in the cavity of the CSET building and performed under real environmental conditions of the DSF. It was measured at $1.05 \mathrm{~m} \mathrm{x} 0.95 \mathrm{~m} \mathrm{x}$ $0.45 \mathrm{~m}$ with two $5 \mathrm{~mm}$ clear glass walls and two wooden sidewalls. There were six blades in the box at a tilt angle of $30^{\circ}$ south facing. Twenty K-type thermocouples and two hot-wire anemometers were implemented at different positions in the test facility as shown in Fig. 7. The continuous data collection was conducted in the summer of 2014 except for rainy days and the time step of the data collection was 5 seconds. 

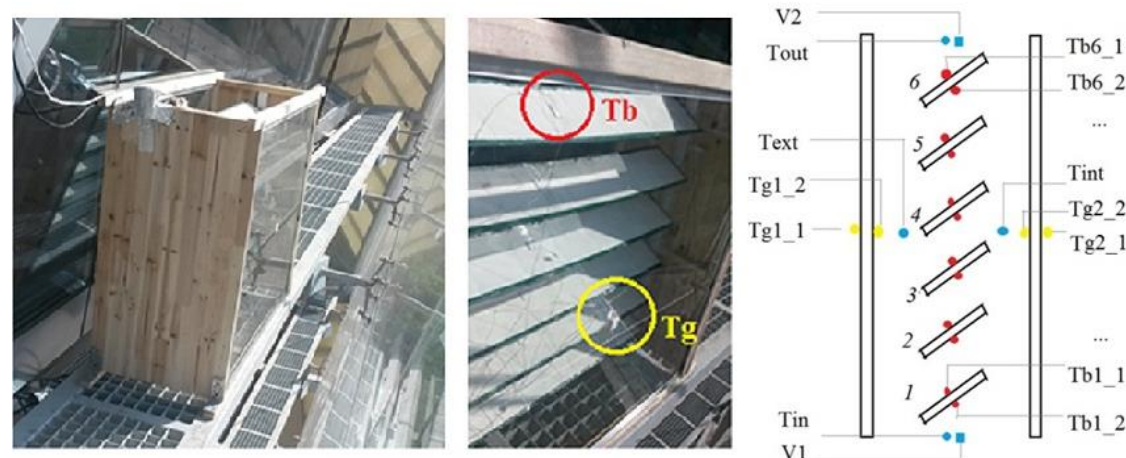

Figure 7: DSF test facility and sensor installation spots

(Tb: surface temperature of the blade; Tg: surface temperature of the DSF glass;

Ta: air temperature; Va: airflow velocity)

The simulated average cavity air temperature has been validated against experimental data on the same day as shown in Fig. 8. In general it was found that the predicted average air temperature agreed reasonably well with the average value of measured data at different positions in DSFs. Tab. 4 compares the surface temperatures of the PCM and aluminium blinds at different positions in DSF. The errors between the simulated and measured data were lower than $4 \%$ and the average difference was $1.31 \%$, which also demonstrates a high accuracy of the simulation results and proved reliability of the numerical models.

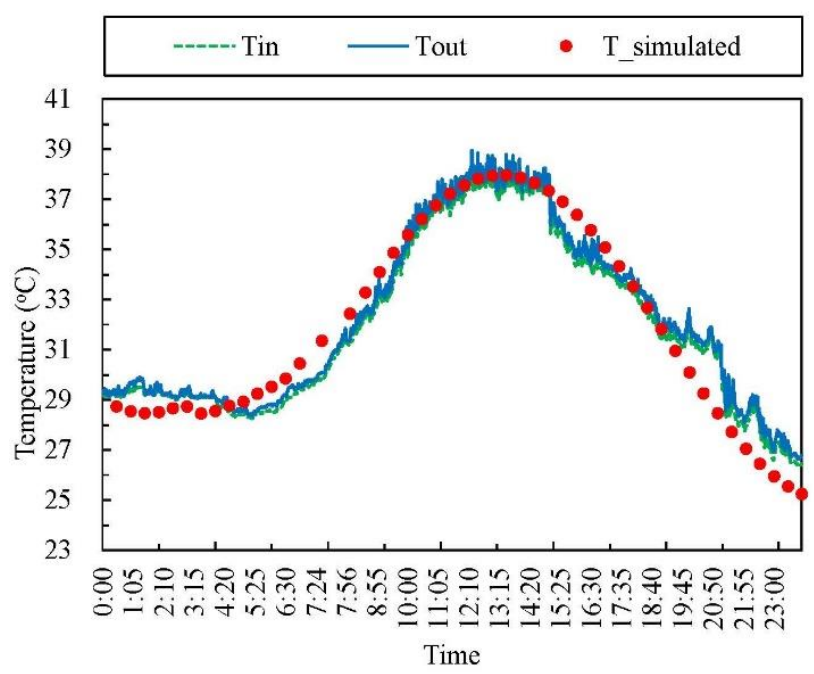

(a) Tin: inlet air temperature; Tout: outlet air temperature; T_simulated: simulated average air temperature 


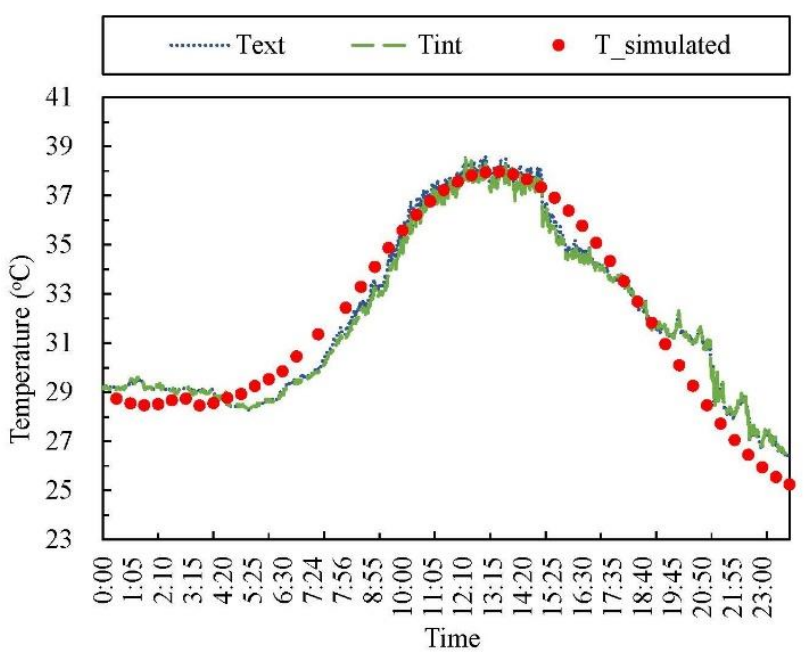

(b) Tint: air temperature near internal glass skin; Text: air temperature near external glass skin; $T$ _simulated: simulated average air temperature

Figure 8: Comparison of simulated and measured DSF air temperatures

Table 4: Comparison of simulated and measured blind surface temperatures

\begin{tabular}{|c|c|c|c|c|c|c|c|c|}
\hline \multirow[t]{2}{*}{ Spot } & \multicolumn{4}{|c|}{ PCM surface temperature } & \multicolumn{4}{|c|}{ Substrate surface temperature } \\
\hline & Simulated & Measured & $\Delta T$ & $\delta \%$ & Simulated & Measured & $\Delta T$ & $\delta \%$ \\
\hline 1 & 37.33 & 36.99 & 0.34 & $0.93 \%$ & 36.07 & 36.84 & 0.76 & $2.07 \%$ \\
\hline 2 & 37.65 & 37.39 & 0.25 & $0.67 \%$ & 36.70 & 37.27 & 0.57 & $1.53 \%$ \\
\hline 3 & 37.96 & 37.40 & 0.56 & $1.49 \%$ & 36.70 & 37.35 & 0.65 & $1.73 \%$ \\
\hline 4 & 38.59 & 37.74 & 0.85 & $2.24 \%$ & 37.33 & 37.34 & 0.01 & $0.04 \%$ \\
\hline 5 & 37.96 & 37.59 & 0.37 & $0.99 \%$ & 37.33 & 37.36 & 0.03 & $0.08 \%$ \\
\hline 6 & 37.33 & 38.59 & 1.26 & $3.27 \%$ & 37.96 & 38.23 & 0.27 & $0.70 \%$ \\
\hline Aver & $\delta \%:$ & & & & & & & $1.31 \%$ \\
\hline
\end{tabular}

\section{$5 \quad$ Results and Discussions}

\subsection{Temperature Profiles}

Fig. 9 compares the average outlet temperature of DSF with PCM blind and aluminium blind. The outlet temperature for both cases increased at the beginning, peaked at 1:30 pm, and then decreased. This demonstrates the combined effect of ambient temperature and solar radiation. In general, the average outlet temperature of DSF with PCM blind was lower than that with the aluminium blind. The temperature difference was larger than $1{ }^{\circ} \mathrm{C}$ from 5:30 am to 7:00 pm and the highest outlet temperature of DSF with PCM blind was about $2.6{ }^{\circ} \mathrm{C}$ lower than that with the aluminium blind. The profiles illustrates that the PCM blind was thermally more effective than the basic aluminium blind since it was able to reduce the DSF outlet temperature. 


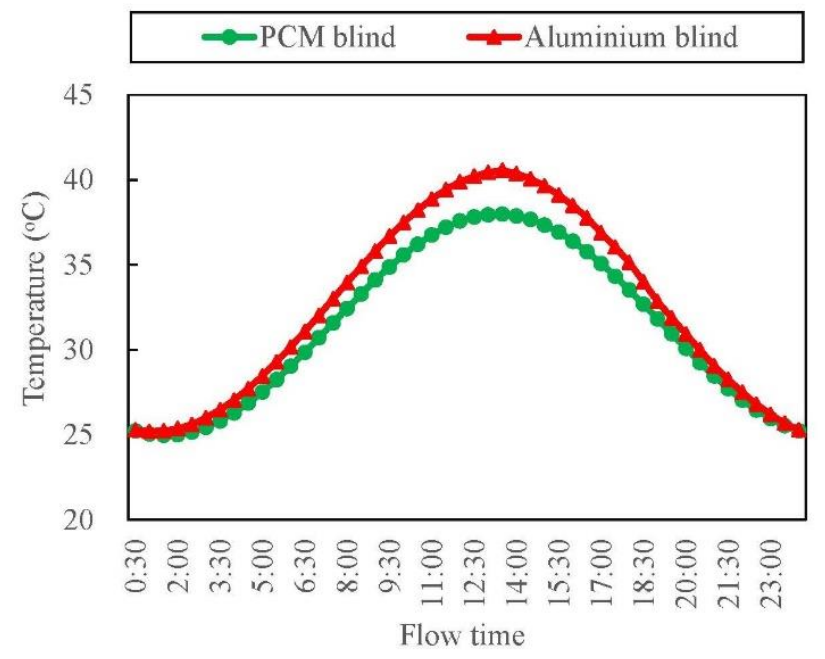

Figure 9: Outlet temperature profiles for DSF with PCM and aluminium blinds

The temperature distributions in the DSFs with PCM and aluminium blinds at different time during a computational cycle were also demonstrated. Fig. 8 shows the temperature contours of DSFs containing PCM (Fig. 10a) and aluminium (Fig. 10b) blind systems. It can be seen that the air temperature in both DSFs increased towards the outlets of the DSFs. However, the air temperature in DSF with the PCM blind was obviously lower than that with the aluminium blind at different times. This indicates that the PCM blind was capable of reducing the cavity air temperature in the DSF than the conventional aluminium blind. In addition, the air temperature around the aluminium blind was about $2{ }^{\circ} \mathrm{C}$ higher than that around the PCM blind. This phenomenon illustrates that unlike the aluminium blind, the PCM blind can store the solar heat during melting process instead of directly releasing it into the DSF cavity.

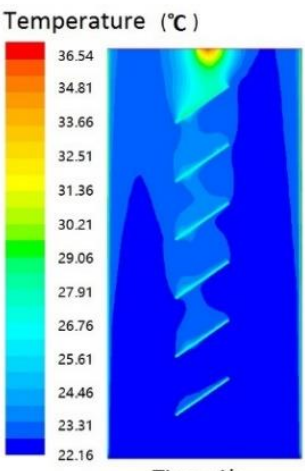

Time=1h

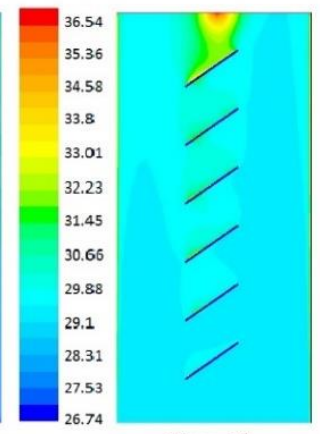

Time=7h

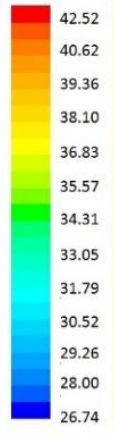

(a) DSF with PCM blind

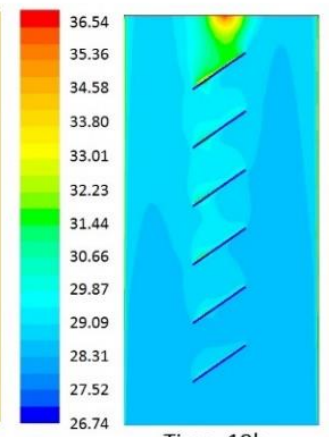

Time $=19 \mathrm{~h}$

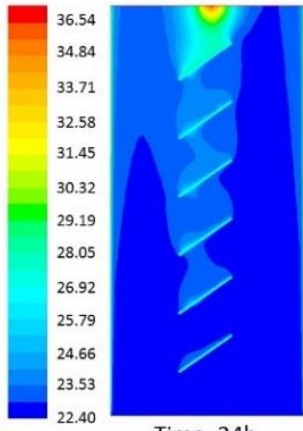

Time $=24 \mathrm{~h}$ 

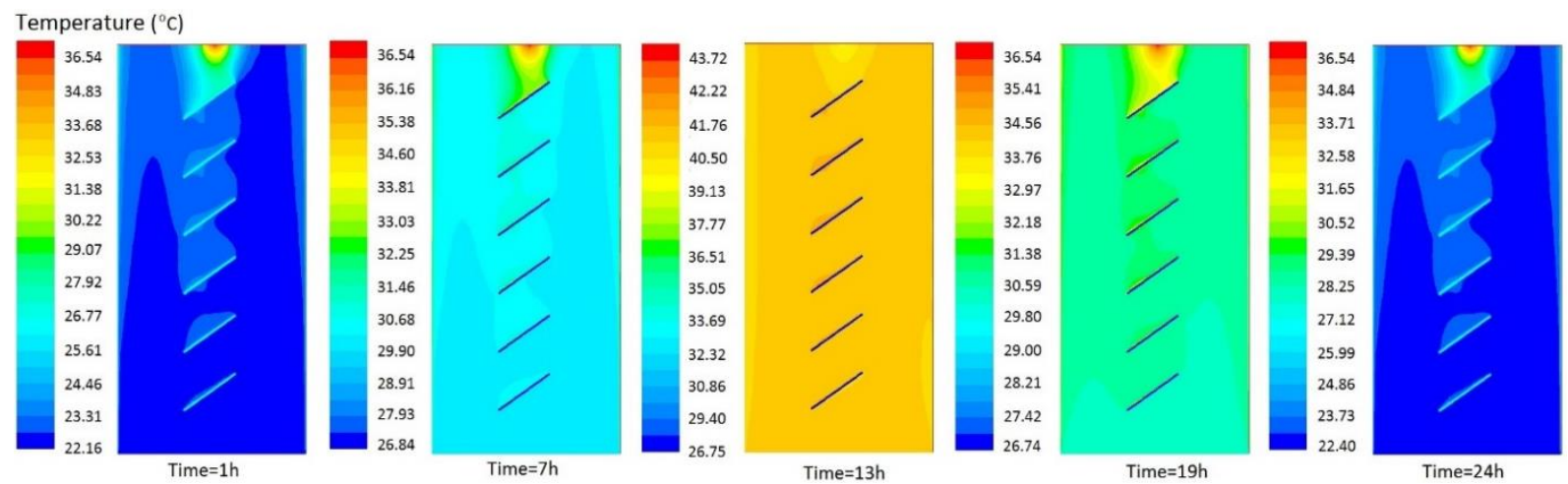

(b) DSF with aluminium blind

Figure 10: Temperature contours of DSF with PCM and aluminium blinds

\subsection{Velocity Profiles}

As shown in Fig. 11, the outlet velocities of DSFs with PCM and aluminium blinds are similar during most of the time. The only difference between the outlet velocities of the two cases occurs when the outlet temperature of the DSFs peaks from time step 48600s (1:00 pm) to 55800s (3:30 pm). During this time range the outlet velocity of DSF with the aluminium blind was $0.516 \mathrm{~m} / \mathrm{s}$ which was a little higher than the outlet velocity of the DSF with PCM blind of $0.484 \mathrm{~m} / \mathrm{s}$. This indicates that unlike the aluminium blind, the PCM blind was able to stabilise the airflow evacuated through the DSF outlet even when the cavity air temperature is high.

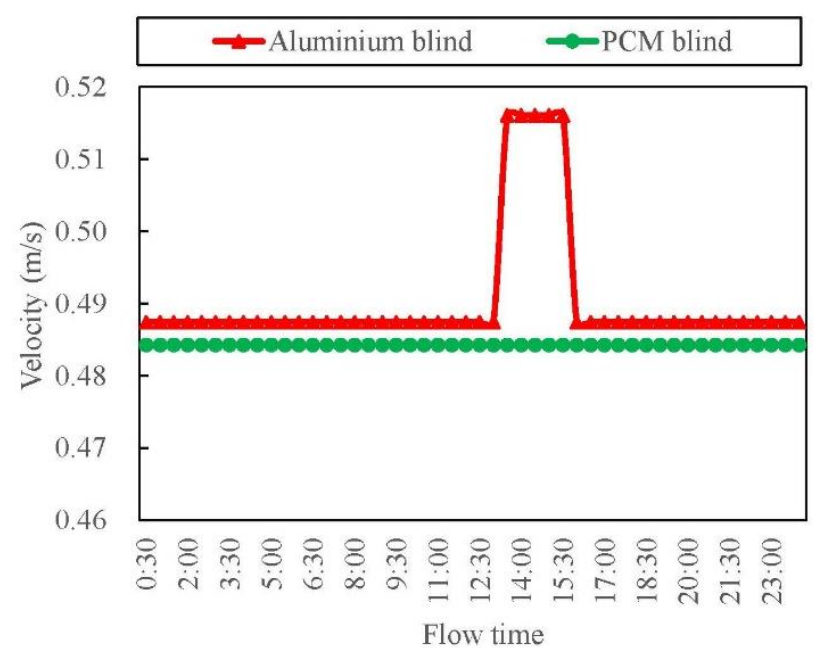

Figure 11: Outlet velocity profiles of DSF with PCM and aluminium blinds

Fig. 12 demonstrates the velocity vectors in DSFs with PCM blind and aluminium blind at time step 52200s (2:30 pm). It could be observed that larger fluctuations of air velocity occurs in DSF with PCM blind as compared with DSF with aluminium blind. This could also be further justified by Fig. 13 which demonstrates 
the velocity profiles along the mid-section of the DSFs at time step 52200s (2:30 pm). It shows that both systems suffered from comparably low air velocity between each two blades which was attributed to low convective heat transfer on surface of the blind. However, larger fluctuations of air velocity within the PCM blind system were found as compared with the aluminium blind. These velocity fluctuations can enhance the convective heat transfer between the cavity air and the PCM blind system as indicated by Chen et, al. [39].

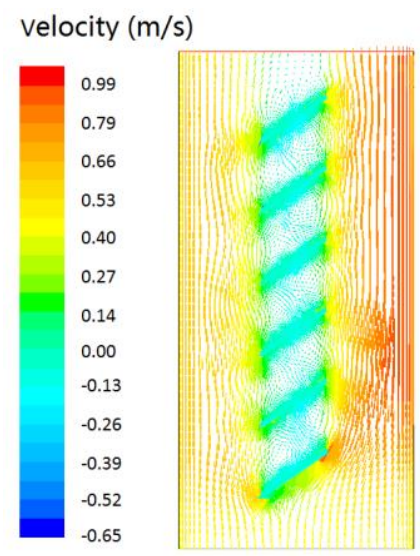

(a) PCM blind

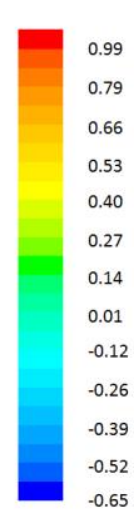

$-0.65$

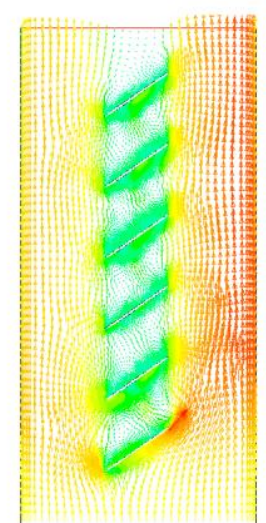

(b) Aluminium blind

Figure 12: Velocity vectors of DSF with PCM and aluminium blinds ( $\mathrm{t}=52200 \mathrm{~s})$

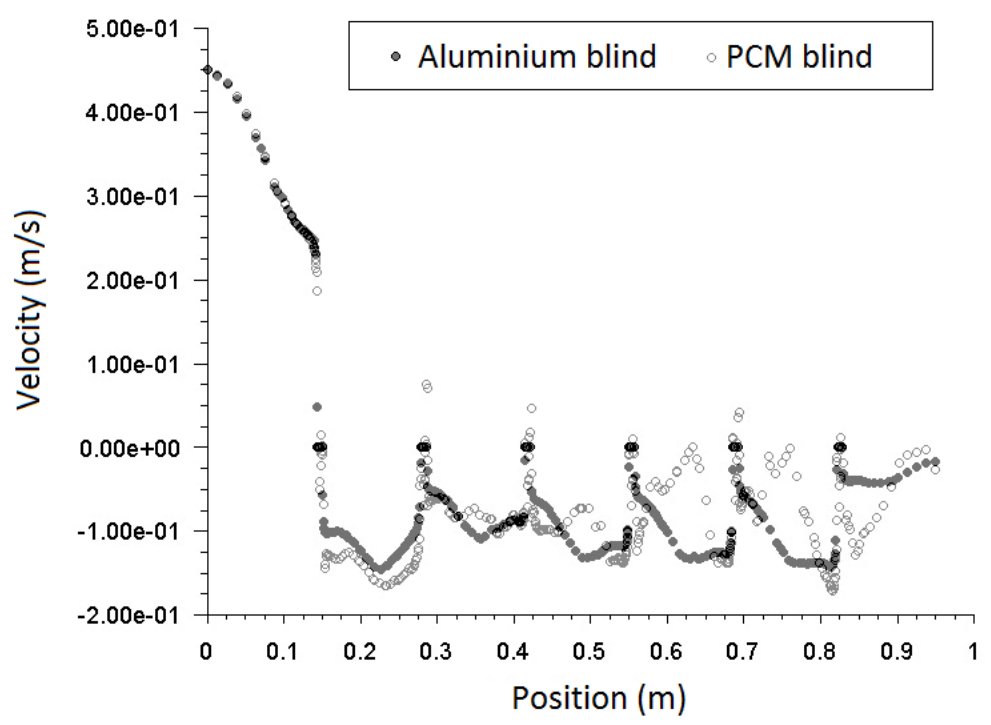

Figure 13: Velocity profiles of DSF with PCM and aluminium blinds ( $\mathrm{t}=52200 \mathrm{~s})$

\subsection{Heat Transfer Profile}

Fig. 14 shows the heat flux profiles of the PCM and aluminium blinds. It can be seen that the PCM blind started to absorb heat from the cavity air from the beginning $(\mathrm{t}=0 \mathrm{~s})$ of the simulation and this process lasted till time step 41400s (11:30 am). In contrast, the aluminium blind re-emitted and released heat from its surface to the 
surroundings during the whole cycle. Therefore compared with the aluminium blind, the PCM blind was able to absorb the solar heat gain in the DSF cavity with its heat storage capacity during the melting process. However, there is still great potential for the PCM blind in capturing more heat in DSF cavity since the absorbing process ended before night-time.

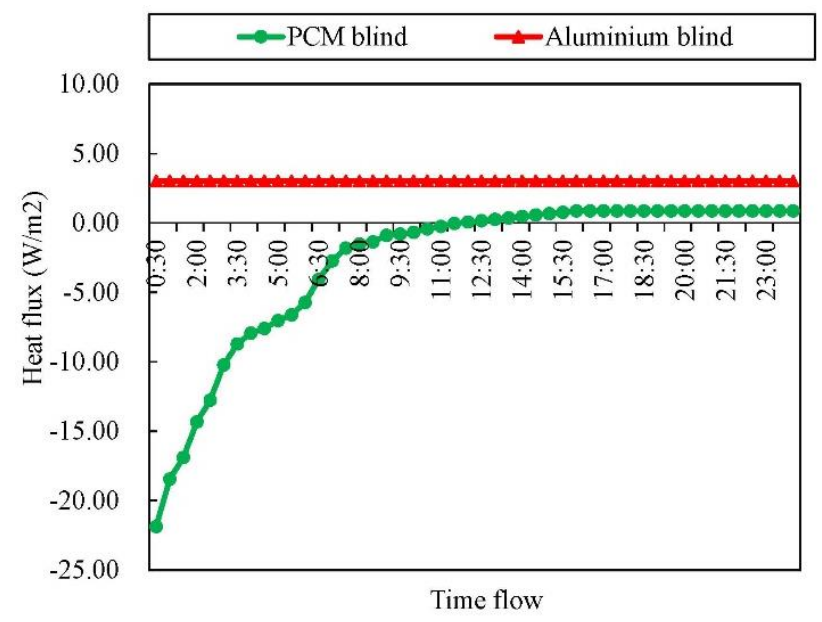

Figure 14: Heat flux profiles of PCM blind and aluminium blind

\section{Conclusions}

In this study, an integrated DSF and PCM blind system was proposed to mitigate the overheating problem in the DSF. The heat transfer in the proposed system was simulated and compared with DSF integrated with conventional aluminium blind under overheating scenario by using ANSYS Workbench FLUENT software. The simulation results were validated by comparing with experimental measurements. In general, this study revealed that the PCM blind system has the potential to be used as an effective thermal management device in DSF systems. The main conclusions are as follow:

- Compared with the basic aluminium blind, the proposed thermal management system based on PCM blind was able to reduce the outlet temperature in DSF while the average air temperature in DSF also decreased. 
- The PCM blind helped to stabilise the outlet airflow of the DSF while improving the convective heat transfer in the DSF between the cavity air and the blind surface.

- The PCM blind can absorb excessive heat from the cavity air thus overcoming the limitation of conventional aluminium blind in re-emitting large amount of solar heat from its high-temperature surface.

\subsection{Limitations of the study}

Although the developed system has demonstrated some level of capacity of minimising the overheating problems in DSFs, there are limitations and future work which can be raised as follow:

- Since the type and quantity of PCM play key roles in the amount of heat which can be captured in DSF cavity [40], there is potential for the PCM blind which can be obtained by raising the number of blades, increasing the thickness of the PCM layer, or replacing the PCM with more thermally effective ones. On the other hand, parameters including the position of the blind and its tilt angle also have impact on the performance of DSF. Thus for achieving higher effectiveness of the integrated DSF and PCM blind system, it would be necessary to conduct further numerical and experimental investigations, and parametric analysis into the impacts and various combinations of the materials, the amount of the materials, dimensions, locations, and tilt angles of the PCM blind system.

- Due to that the geometry and input data of the simulation is from DSF test facility with small dimensions to represent a facade unit, it is necessary to conduct simulations for entire façades of different geometry and dimensions in future study to include different types of DSFs. Besides, there is the need for longer term experimental investigations into the energy storage efficiency of the PCM due to repeated charging and discharging cycling. 
- Given different climatic regions and weather conditions, investigations should also be carried out on the interactions of the integrated system with DSF building operation strategies such as the control strategies of HVAC system. The effectiveness of the integrated system should also be tested under various climatic conditions for wider applications.

- Finally, life cycle assessment of the developed integrated thermal management system is essential in order to obtain full technical and economic evaluation.

\section{REFERENCES}

[1] A. M. Omer, Green energies and the environment, Renewable and Sustainable Energy Reviews, vol. 12, pp. 1789-1821, 2008.

[2] R. Pacheco, J. Ordóñez, and G. Martínez, Energy efficient design of building: A review, Renewable and Sustainable Energy Reviews, vol. 16, pp. 3559-3573, 2012.

[3] J. Zhou and Y. Chen, A review on applying ventilated double-skin facade to buildings in hot-summer and cold-winter zone in China, Renewable and Sustainable Energy Reviews, vol. 14, pp. 1321-1328, 2010.

[4] H. Poirazis, Double Skin Facades: A Literature Review, A report of IEA SHC Task 34 ECBCS Annex 43, 2006, 2006.

[5] Y.-M. Kim, J.-H. Lee, S.-M. Kim, and S. Kim, Effects of double skin envelopes on natural ventilation and heating loads in office buildings, Energy and Buildings, vol. 43, pp. 2118-2126, 2011.

[6] M. H. Tascon, Experimental and Computational Evaluation Of Thermal Performance and Overheating in Double Skin Facades, Thesis submitted to the University of Nottingham for the degree of Doctor of Philosophy, 2008.

[7] W. Jager, Double Skin Facades-Sustainable Concepts. Presentation of Hydro for Syd Bygg 2003, Malmo, Sweden, 2003.

[8] M. Wigginton, Intelligent Glass Facades by Andrea Compagno 4th edition Birkhäuser, Basel, 1999160 pp., 80 colour, 240 line illus. arq: Architectural Research Quarterly, vol. 3, 2008.

[9] A. Fallahi, F. Haghighat, and H. Elsadi, Energy performance assessment of double-skin façade with thermal mass, Energy and Buildings, vol. 42, pp. 1499-1509, 2010.

[10] D. P. Bentz and R. Turpin, Potential applications of phase change materials in concrete technology, Cement and Concrete Composites, vol. 29, pp. 527-532, 2007.

[11] A. de Gracia, L. Navarro, A. Castell, Á. Ruiz-Pardo, S. Alvárez, and L. F. Cabeza, Experimental study of a ventilated facade with PCM during winter period, Energy and Buildings, vol. 58, pp. 324-332, 2013.

[12] A. de Gracia, L. Navarro, A. Castell, Á. Ruiz-Pardo, S. Álvarez, and L. F. Cabeza, Thermal analysis of a ventilated facade with PCM for cooling applications, Energy and Buildings, vol. 65, pp. 508-515, 2013.

[13] S. Saber, Energy efficiency and thermal comfort influences of alternatives of SSF and DSF in tropical bungalow house, International Journal of Physical Sciences, vol. 7(9), p. 15, 23 February, 2012.

[14] X. Kong, S. Liu, H. Yang, Y. Zhong, C. Qi, An experimental study of all-season operation strategy for a respiration-type double-layer glass curtain wall system in cold zone of China, Building and Environment, vol. 97, pp. 166-176, 2016

[15] Z. Zeng, X. Li, C. Li, and Y. Zhu, Modeling ventilation in naturally ventilated double-skin façade with a venetian blind, Building and Environment, vol. 57, pp. 1-6, 2012. 
[16] F. Xue, X. Li, A fast assessment method for thermal performance of naturally ventilated double-skin facades during cooling season, Solar Energy, vol. 114, pp. 303-313, 2015.

[17] A. Ghaffarianhoseini, A. Ghaffarianhoseini, U. Berardi, J. Tookey, D. H. W. Li, S. Kariminia, Exploring the advantages and challenges of double-skin façades (DSFs), Renewable and Sustainable Energy Reviews, vol. 60, pp. 1052-1065, 2016

[18] M. Haase and A. Amato, A study of the effectiveness of different control strategies in double skin facades in warm and humid climates, Journal of Building Performance Simulation, vol. 2, pp. 179-187, 2009.

[19] Matthias Haase, Felix Wong, Alex Amato, Double-skin facades for Hong Kong, Surveying and Built Environment, 2007.

[20] Nassim Safer, Jean Jacques Roux, M. W., Three-dimensional simulation with a CFD tool of the airflow phenomena in single floor double-skin facade equipped with a venetian blind, Solar Energy, vol. 79, p. $11,2005$.

[21] E. Gratia and A. De Herde, The most efficient position of shading devices in a double-skin facade, Energy and Buildings, vol. 39, pp. 364-373, 2007.

[22] T. E. Jiru, Y.-X. Tao, and F. Haghighat, Airflow and heat transfer in double skin facades, Energy and Buildings, vol. 43, pp. 2760-2766, 2011.

[23] C. Shen, X. Li, Solar heat gain reduction of double glazing window with coolingpipes embedded in venetian blinds by utilizing natural cooling, Energy and Buildings, vol. 112, pp. 173-183, 2016.

[24] H. Akeiber, P. Nejat, M. Z. A.Majid, M. A.Wahid, F. Jomehzadeh, I. Z. Famileh, J. K. Calautit, B. R. Hughes, S. A. Zaki, A review on phase change material (PCM) for sustainable passive cooling in building envelopes, Renewable and Sustainable Energy Reviews, vol. 60, pp. 1470-1479, 2016

[25] H. Weinlaeder, W. Koerner, and M. Heidenfelder, Monitoring results of an interior sun protection system with integrated latent heat storage, Energy and Buildings, vol. 43, pp. 2468-2475, 2011.

[26] K. Darkwa and J. S. Kim, Heat transfer in neuron composite laminated phase-change drywall, Proceedings of the Institution of Mechanical Engineers, Part A: Journal of Power and Energy, vol. 218, pp. 83-87, 2004.

[27] K. Darkwa, Quasi-isotropic laminated phase-change material system, Applied Energy, vol. 84, pp. 599607, 2007.

[28] Data Sheet PX35, R. T. GmbH, Ed., ed, 2013.

[29] C.-S. Park, G. Augenbroe, T. Messadi, M. Thitisawat, and N. Sadegh, Calibration of a lumped simulation model for double-skin façade systems, Energy and Buildings, vol. 36, pp. 1117-1130, 2004.

[30] J. Z. Yuan Yuan, Yingxin Zhu, Borong lin, A lumped model of double skin facade with cavity shading, Proceedings: Building Simulaiton, 2007.

[31] K.-i. K. Jun Tanimoto, Simulation study on an air flow window system with an integrated roll screen, Energy and Buildings, vol. 26, 1997.

[32] D. Saelens, S. Roels, and H. Hens, The inlet temperature as a boundary condition for multiple-skin facade modelling, Energy and Buildings, vol. 36, pp. 825-835, 2004.

[33] T. E. Jiru and F. Haghighat, Modeling ventilated double skin façade-A zonal approach, Energy and Buildings, vol. 40, pp. 1567-1576, 2008.

[34] Theory Guide, in FLUENT in Workbench User's Guide, ed, 2011.

[35] Y. A. Cengel, Heat transfer: A practical approach: McGraw-Hill, 2003.

[36] D. Brandl, T. Mach, M. Grobbauer, and C. Hochenauer, Analysis of ventilation effects and the thermal behaviour of multifunctional façade elements with 3D CFD models, Energy and Buildings, 2014.

[37] J. Darkwa, Y. Li, and D. H. C. Chow, Heat transfer and air movement behaviour in a double-skin façade, Sustainable Cities and Society, 2013.

[38] J. Darkwa and Y. Li, Thermal Simulation and Evaluation of a Double Skin Façade System, presented at the 11th International Energy Conversion Engineering Conference, San Jose, CA, 2013. 
[39] T.Y.Chen, R.K.Du, Effects of velocity fluctuations on heat transfer enhancement, Experiments in Fluids, vol. 34, 2003.

[40] G. Evola, L. Marletta, F. Sicurella, A methodology for investigating the effectiveness of PCM wallboards for summer thermal comfort in buildings, Building and Environment, vol. 59, pp. 517-527, 2013. 